\title{
Enhancing the Cell Growth Using Conductive Scaffolds
}

\author{
Nuha Al Habis ${ }^{1 *}$, Lafdi $K^{1}$, Tsonis PA $^{2}$ and Rio-Tsonis KD
}

${ }^{1}$ Department of Materials Engineering, University of Dayton, 300 College Park, Dayton, Ohio 45440, USA

${ }^{2}$ Department of Biology, Center for Tissue Regeneration and Engineering, University of Dayton, Dayton, Ohio 45469, USA

${ }^{3}$ Department of Biology, Center for Visual Sciences, Miami University, Oxford, Ohio 45056, USA

\begin{abstract}
Conductive biopolymers are starting to emerge as potential scaffolds of the future. These scaffolds exhibit some unique properties such as inherent conductivity, mechanical and surface properties. In this paper, Bio-conductive material were made using three types of carbon nano-fillers including carbon black, nanofiber and graphene. These were mixed with polycaprolactone to fabricate various scaffolds. A human lens epithelial cell was seeded on top of these scaffolds to assay the cell growth. The study of cell growth as a function of concentration, type and orientation of nanofillers and their conductivities was investigated. We found that these biopolymer nanocomposites have a positive effect on cell density. Regardless of the scaffold shape (film or fiber) and the additive's type, when the concentration of nanoadditives increased, the electrical conductivity and cell density also increased. For a given nano-additive concentration and type, cell density seems to be higher in scaffolds with fiber shape vs. the film shape. However, as the conductivity of the nano-additives increased, so did cell density.
\end{abstract}

Keywords: Carbon nano-additives; Electrical properties of nanoadditives; Conductive scaffold; Cell density

\section{Introduction}

Scaffolds were generated as substrate structures for tissue repair and regeneration [1,2]. Scaffolds can be formed by utilizing biopolymers, conductive materials and polymer-based additives which can provide additional features such as surface, mechanical and electrical properties. Synthetic polymers are commonly used for the fabrication of nanofiber scaffolds. In this study, we explored their use as biodegradable materials for scaffolds. These include poly (lactic acid) (PLA), poly (lactic-co-glycolic acid) (PLGA), Polycaprolactone (PCL), poly (methyl methacrylate) (PMMA), polyglycolic acid (PGA), and polyvinyl alcohol (PVA). Polymer scaffolds can be combined with growth factors. These polymer scaffolds have been used for numerous applications, including regeneration of blood vessels (i.e. coronary arteries), bone, skin, cartilage, as well as to enhance cell proliferation and differentiation [3-5]. Another material that has shown rapid expansion among biocompatible scaffolds are electroactive materials. These materials hold a great promise for cell growth and tissue repair. Conductive scaffolds have been considered suitable substrates for cell proliferation and cell attachment [6], and they enhanced the effect of electrical signals on cell activities $[7,8]$. For instance, when biocompatible polypyrrole (PPY) film was applied to rat bone marrow stromal cells in culture, the electron mobility, electrical conductivity and calcium deposition into the extracellular matrix increased due to the highly-branched PPy chains of the film [9]. Furthermore, the electroactive and biodegradable blend polymer (PLLA/ PGTA) was able to differentiate rat $\mathrm{C} 6$ glioma cells rapidly [10]. Finally, carbon nano-fillers have a broad range of usage in biological applications as scaffolds $[11,12]$ to enhance cell differentiation $[13,14]$ due to their compatibility and electrical and mechanical properties $[15,16]$. These fillers, in particular, carbon black (CB), carbon nanofiber (CNF) and graphene, have a variety of characteristics that rely on their crystal structure and geometrical configuration [17]. CB is extensively used as a filler in elastomers, plastic and paints to modify the mechanical, electrical and the optical properties of the materials [18]. CB has a spherical particle form, obtained by the partial combustion or thermal decomposition of hydrocarbons [19]. It has a large surface area and an aggregate dimension that ranges from tens of nanometers to a few hundred nanometers. When added to another component, it imparts its distinctive features to improve the mechanical and electrical properties of the nanocomposite [20]. In addition, CNF can be primarily fabricated by catalytically vaporizing deposition growth and electrospinning approaches [21]. CNF has a cylindrical nanostructure with a high aspect ratio, excellent thermal conductivity, mechanical, and electrical properties which used as additives in various structural materials. The potential of using carbon-based nanofibers as reinforcement was realized in the 1980s [22-25]. The most reliable filler is graphene which consists of interconnected hexagon carbon atoms and forms lamella. Rolling graphene structures carbon nanotubes along certain axes which allow graphene to be structurally linked to many carbon allotropes [26]. In the last ten years, graphene has been one of the most studied materials due to its unique electrical, optical, and mechanical properties as well as for its potential applications [27]. Graphene can be prepared by exfoliation, epitaxial growth and chemical vapor deposition methods [28].

PCL nanocomposite based carbon nano-fillers were fabricated by using electrospinning and spin coating techniques. It is known that electrospinning can improve cell proliferation. Yang et al. studied the behavior of neural stem cells (NSC) with an aligned electrospun nanofiber scaffold of poly (l-lactic acid) (PLLA). The results showed that the direction of PLLA fibers had a parallel control on the direction of NSC elongation and their neurite outgrowth [29]. Furthermore, to understand the behavior and interaction of cells with scaffolds, the orientation and alignment of the scaffold morphology were studied. For example, Sharma et al. achieved a significant effect of $80 \%$ elongation of cells on the scaffold by using micropatterned polymeric films [30]. Moreover, directed axonal and nerve regeneration has been promoted

*Corresponding author: Nuha Al Habis, Department of Materials Engineering University of Dayton, 300 College Park, Dayton, Ohio 45440, USA, Tel: 937-2291000; E-mail: alhabisn1@gmail.com

Received: March 25, 2018; Accepted: April 03, 2018; Published: April 06, 2018

Citation: Al Habis N, Lafdi K, Tsonis PA, Rio-Tsonis KD (2018) Enhancing the Cell Growth Using Conductive Scaffolds. J Nanomed Nanotechnol 9: 493. doi: 10.4172/2157-7439.1000493

Copyright: (c) 2018 Al Habis N, et al. This is an open-access article distributed under the terms of the Creative Commons Attribution License, which permits unrestricted use, distribution, and reproduction in any medium, provided the original author and source are credited. 
by using micropatterned scaffolds [31,32]. Zhou et al. demonstrated that a scaffold of electrospun aligned PLLA fibers coated with PGlu-codoped PPy film significantly enhanced neurite's extensions by 68\% [33]. Recently, numerous research studies have been examining the effects of electrical conductivity and electrical stimulation of the cells. PLLA fibers have also been known to regulate cell attachment, proliferation, and differentiation of nerve cell axonal extension [34], healing of bones [35], cartilage [36], skin, connective tissues [37], cranial, spinal [38,39] and peripheral nerves $[40,41]$. In a study by Schmidt et al., the effect of electrical stimulus through a scaffold film was recorded in muscle and neuronal cells [42]. Polypyrrole (PPy) film appeared to have a slight adverse tissue response compared to poly (lactic acid-co-glycolic acid). Another study used CNT grid as conductive scaffolds to demonstrate the effect of neuronal circuit growth, by significantly increasing the efficacy of neural signal transmission [43]. On the other hand, Keisham et al. used graphene as a noninvasive tool for early cancer diagnosis due to its large quantum capacitance and the electronic properties. The result demonstrated the ability of graphene membrane to differentiate a single hyperactive cancerous cell from a normal cell by integrating brain cells onto graphene substrate [44].

In this work, we explore the effect that scaffold orientation and conductivity has on cell growth. The orientation was altered using processing methods such as electrospinning and spin coating. On the other hand, the conductivity was tailored using three carbon nanofillers (CNF, CB and graphene) at various concentrations.

\section{Materials and Experimental Methods}

\section{Materials}

Polycaprolactone (PCL), $\left(\mathrm{M}_{\mathrm{w}}=80,000\right)$ is a semi-crystalline nontoxic hydrophobic biodegradable polyester supplied by Sigma Aldrich Corporation. Nano-fillers that used in this study are carbon nanofiber (CNF), carbon black (CB) and graphene. CNF was provided by Pyrograf Products Inc. which was dispersed in a polymer to provide a conductive network by approximately $5 \times 10^{-5} \Omega . \mathrm{cm}$ [45]. The average outer diameter of CNF is $125-150 \mathrm{~nm}$, and the average specific surface area is $65-75 \mathrm{~m}^{2} / \mathrm{g}$. CB is a high conductive (Vulcan XC 72R) powder obtained from Cabot $^{\circledR}$ Corporation with a particle size of $300 \mathrm{~nm}$ and $1.9 \mathrm{Ohm}-\mathrm{cm}$ volume conductivity at $23^{\circ} \mathrm{C}$. The electrical conductivity of CB is $9.30 \mathrm{~S} / \mathrm{cm}$ [46]. Exfoliated graphene produced by thermal shock or rapid temperature change of the intercalated graphite compound, which was previously described [47]. The surface area of the small, medium and large exfoliated graphite is 16.02, 15.61 and $15.35 \mathrm{~m}^{2} / \mathrm{g}$ respectively and has an electrical conductivity of about 2.8 $3.2 \mathrm{kS} / \mathrm{m}$ [48]. Acetone was used as a solvent which formed PCL/nanofiller solution. Eagle's Minimum Essential Medium EMEM (ATCC ${ }^{\circ}$ 30-2003 ${ }^{\mathrm{mm}}$ ) and Fetal Bovine Serum (FBS) (ATCC ${ }^{\oplus} 30-2020^{\mathrm{mm}}$ ) were used as a growth medium for the cell. Human lens epithelial cell B-3 (ATCC ${ }^{\circ}$ CRL-11421 $1^{\mathrm{sx}}$ ), Neutral Buffered Formalin (10\%) (Thermo Scientific ${ }^{\mathrm{mm}}$ Richard-Allan Scientific ${ }^{\text {tix }}$ ), 1X phosphate buffered saline (PBS) and ProLong ${ }^{\circledR}$ Diamond Antifade Mountant with DAPI (Molecular Probes ${ }^{\mathrm{m}}$ by life technologies) were used to characterize the cell.

\section{Fabrication of conducting scaffold}

Scaffolds were prepared by mixing $14 \mathrm{wt} \%$ PCL and the nano-filler. Five different weight percentages of nano-filler were dispersed in 5 $\mathrm{ml}$ of acetone which was ultra-sonicated for two days. Following the ultrasonication process, a solution of $0.644 \mathrm{~g}$ PCL and $5 \mathrm{ml}$ acetone, which were stirred at a temperature of $65^{\circ} \mathrm{C}$ for $2 \mathrm{~h}$. A spin coater method (Speed line P2604 Technologies) was used to produce a PCL/ nano-fillers thin film scaffold using a Spin speed of $3000 \mathrm{rpm}$ for 90 seconds. The electrospinning method was used to fabricate a PCL/ nano-filler nano-fibrous scaffolds, which was performed using a syringe pump (New Era Pump Systems, Inc. NE-300), voltage controller (Stanford research systems, Inc. Model PS375), rotator (Dayton ${ }^{\circledR}$ DC Motor, 4Z145), rotator controller (Mastech, HY3010E), and a syringe (30 mL Luer-Lor ${ }^{\text {mo }}$ Syringe, BD), 17\# needle. The voltage between the needle and the collector was $15 \mathrm{kV}$ with a distance of $15 \mathrm{~cm}$, a feeding rate of $0.003 \mathrm{~mL} / \mathrm{min}$, and a rotator speed of $5.7 \mathrm{~m} / \mathrm{s}$. The $\mathrm{PCL} /$ acetone solution was $14 \%$ by weight.

\section{Electrical measurement}

Based on our previous work [49], spin coating film conductivity was tested by using a two-probe method with copper electrodes and a KEITHLEY 2700 multimeter/DATA acquisition system with a range of operation $(1 \mu \mathrm{A}-1 \mathrm{~mA}, 0-12.8 \mathrm{~V})$. In this device, the lowest values are used for lowest energy across the sample. The area of the measurement through the sample was $1.5 \times 10^{-9}$ to $3.5 \times 10^{-8}$ The thickness of the films were measured by a thermal mechanical analysis (TMA, Q400, TA Universal) at room temperature $\left(\sim 23^{\circ} \mathrm{C}\right)$ which is between $0.3-7$ $\mu \mathrm{m}$. The conductivity of the electrospinning fibers does not measure in this work due to unavailable tools to test the conductivity of the single fiber.

\section{Cell culture and seeding}

Transformed human lens epithelial (HLE) cells B-3 (ATCC) were cultured in Eagle's Minimum Essential Medium (EMEM) supplemented with $20 \%$ fetal bovine serum (FBS). HLE B-3 frozen cells were thawed in a $37^{\circ} \mathrm{C}$ water bath with keeping the O-ring and cap out of the water to avoid any contamination for 2 minutes. Once thawed, the cells were aseptically transferred to $50 \mathrm{ml}$ tubes with $10 \mathrm{ml}$ of the culture media and centrifuged at approximately $125 \mathrm{x}$ g for $5-10$ minutes to remove cryoprotective agents. The cells were resuspended in $20 \mathrm{ml}$ of fresh growth medium, plated into a $75 \mathrm{~cm}^{2}$ tissue culture flasks and incubated in $5 \% \mathrm{CO}_{2}$ at $37^{\circ} \mathrm{C}$.

\section{Sub-culturing procedure}

After 5-7 days of incubation, the cells were sub-cultured by separating the cells from the dish using the enzyme Trypsin for less than 30 seconds. The process was repeated for 60 seconds at room temperature. Complete growth medium was then added to neutralize the trypsin and the contents were placed in a centrifuge tube. The contents were centrifuged at approximately $125 \mathrm{x}$ g for 5-10 minutes. The medium and trypsin were aspirated and new media was added to resuspend the cells. At this time, the cells were ready to culture on biomaterial scaffold. After calculating the number of viable cells, a dilution ratio was applied to well plates containing the different scaffold along with growth media. The cells were, incubated for 24, 72 and 120 hours

\section{Fixing adherent cells}

Cells grown on scaffolds were fixed with $10 \%$ Neutral Buffered formalin for 10 minutes. The scaffolds were then rinsed twice with $1 \mathrm{X}$ phosphate buffered saline (PBS). To stain cell nuclei, the scaffoldcell interfaces were incubated with one drop of prolong ${ }^{\circledR}$ diamond antifade mountant containing DAPI (Life technologies corporation) on microscope slides.

\section{Characterization}

A Phenom Desktop scanning electron microscope (SEM) (Pro 
$\mathrm{X}$, Phenom) was used to characterize the morphology of nano-fillers and scaffolds. X-ray diffractometer (Smart lab Rigaku) was used to characterize the crystallinity of the raw materials. A fluorescence microscope (MF53, Nikon) was used to characterize cell density. Cell images were analyzed by ImageJ software. The cell density was estimated by counting DAPI+ cells in each dish and calculating the average of the integrated density.

\section{Results and Discussion}

We have characterized several scaffolds made up of three types of carbon nano-fillers including $\mathrm{CB}, \mathrm{CNF}$ and graphene that have unique properties to improve cell growth. As shown in Figure 1, the morphology of $\mathrm{CB}, \mathrm{CNF}$ and graphene was characterized. Using dark field imaging, we show that carbon black consists of spherical nanoparticles in which these particles are arranged in the form of onion-like structure (inset: the model of Heidenreich) (Figure 1a) [50]. These particles have an average dimension of $300 \mathrm{~nm}$. Figure $1 \mathrm{~b}$ shows the morphology of CNF with a diameter of around $150 \mathrm{~nm}$ and graphene platelets are made of thin carbon sheets with a majority ranging between 15-20 um in length and width (Figure 1c).

All these nanoparticles were mixed into polycaprolactone matrix to fabricate various samples by electrospinning and spin coating methods. The morphology of electrospinning fibers of PCL/1 wt $\%$ of $\mathrm{CB}, \mathrm{CNF}$ and graphene composites is shown in Figure 2. All spun fibers were produced with some degree of alignment and different diameters. The nanofibers were smaller in size in the case of $\mathrm{CB} / \mathrm{PCL}$ vs. $\mathrm{CNF} / \mathrm{PCL}$ and
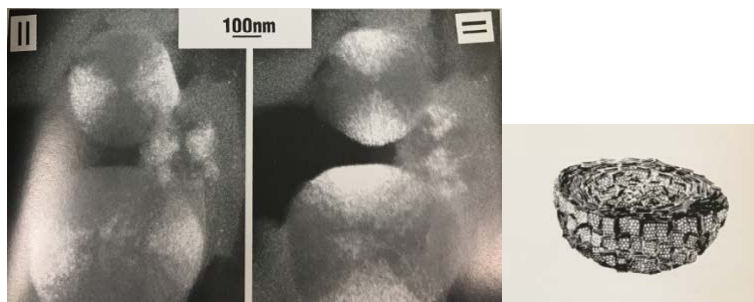

Figure 1a: SEM of Dark field imaging shows the onion like the structure of carbon black (CB) [50].

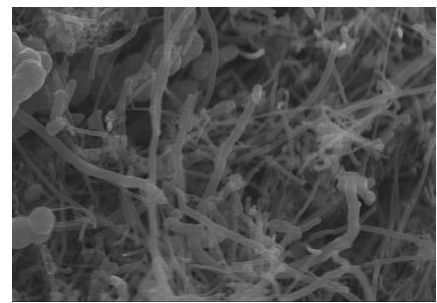

Figure 1b: SEM morphology of carbon nanofibers (CNF)
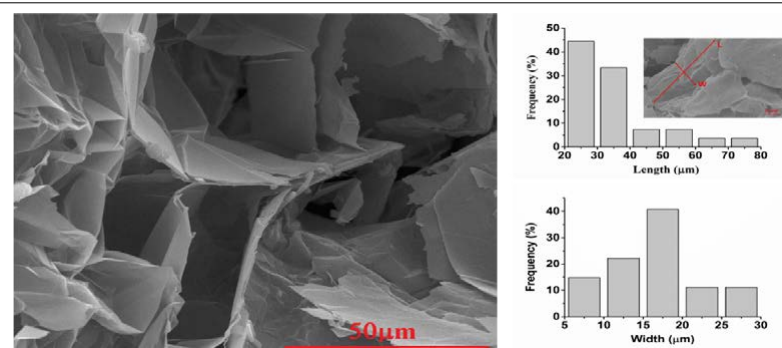

Figure 1c: SEM morphology of graphene platelets.

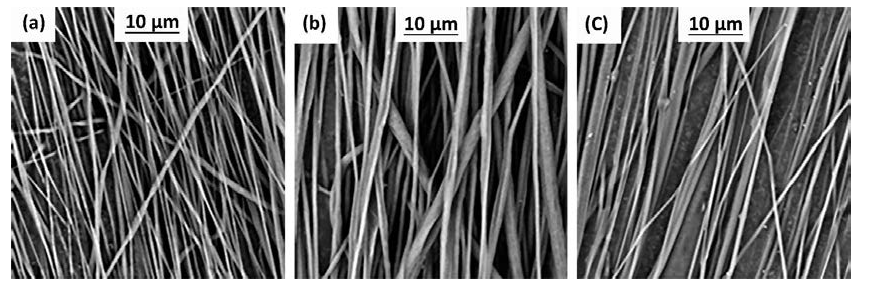

Figure 2: SEM images of electrospinning based fibers of (a) CB/PCL, (b) CNF/ $\mathrm{PCL}$, (c) graphene/PCL.
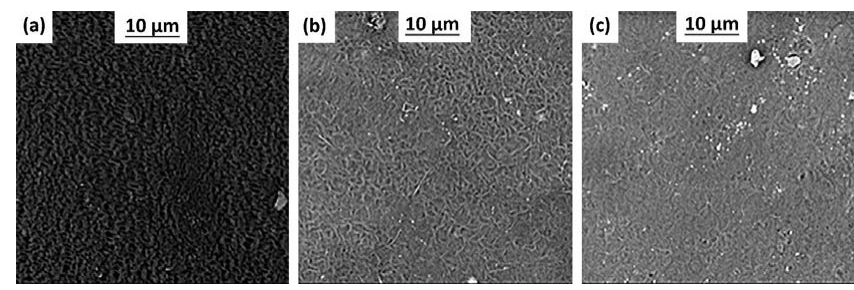

Figure 3: SEM images of spin coating based samples of (a) CB/PCL, (b) CNF/ $\mathrm{PCL}$ and (c) graphene/PCL.

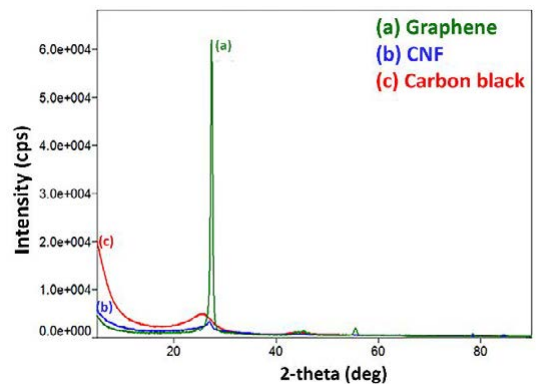

Figure 4: XRD measurements of (a) graphene, (b) CNF and (c) CB.

graphene/PCL fibers. The difference in dimension might be due to the nano-additive aspect ratio and their dispersion into PCL.

Conversely, spin coating based films of $1 \mathrm{wt} \% \mathrm{CB} / \mathrm{PCL}, \mathrm{CNF} / \mathrm{PCL}$, graphene/PCL nano-composite are shown in Figure 3. The ringed shape shown in these pictures represents the nano-additive network. $\mathrm{CB} / \mathrm{PCL}$ based nanocomposite films show a larger porous area with relatively fewer aggregates than CNF/PCL. However, graphene/PCL films show the best compromise with better dispersion and a little porosity.

The crystallinity characterization of the raw materials was measured by X-ray diffraction. X-ray diffractograms were recorded in ranges of $5-90^{\circ}(2 \theta)$ angles. As shown in Figure $4 \mathrm{a}$, the XRD pattern of graphene is characterized by a strong, sharp peak with high intensity at $27.409^{\circ}$ which corresponds to (002) crystallographic plane which is equal to published data [51]. It indicates a higher ordered structure which refers to have the highest conductivity. Conversely, XRD spectrum of CNF and $\mathrm{CB}$ shows less carbon order (Figure 4). Both of these nano-additives were made of turbostratic carbons with relatively low crystallinity.

We wanted to test if the manufactured scaffolds favored cell growth, therefore, we seeded an equal amount of human lens epithelial cells (B-3 cell line) to each of the prepared scaffolds. Samples were made by electrospinning and spin coating with various concentrations of nanofiller. Cell growth was carried out for a period of 24, 72 and 120 hours (Figure 5). Cells were then visualized using the nuclear stain DAPI under a fluorescent microscope. We noted that for the same 
Citation: Al Habis N, Lafdi K, Tsonis PA, Rio-Tsonis KD (2018) Enhancing the Cell Growth Using Conductive Scaffolds. J Nanomed Nanotechnol 9: 493. doi: $10.4172 / 2157-7439.1000493$

Page 4 of 6

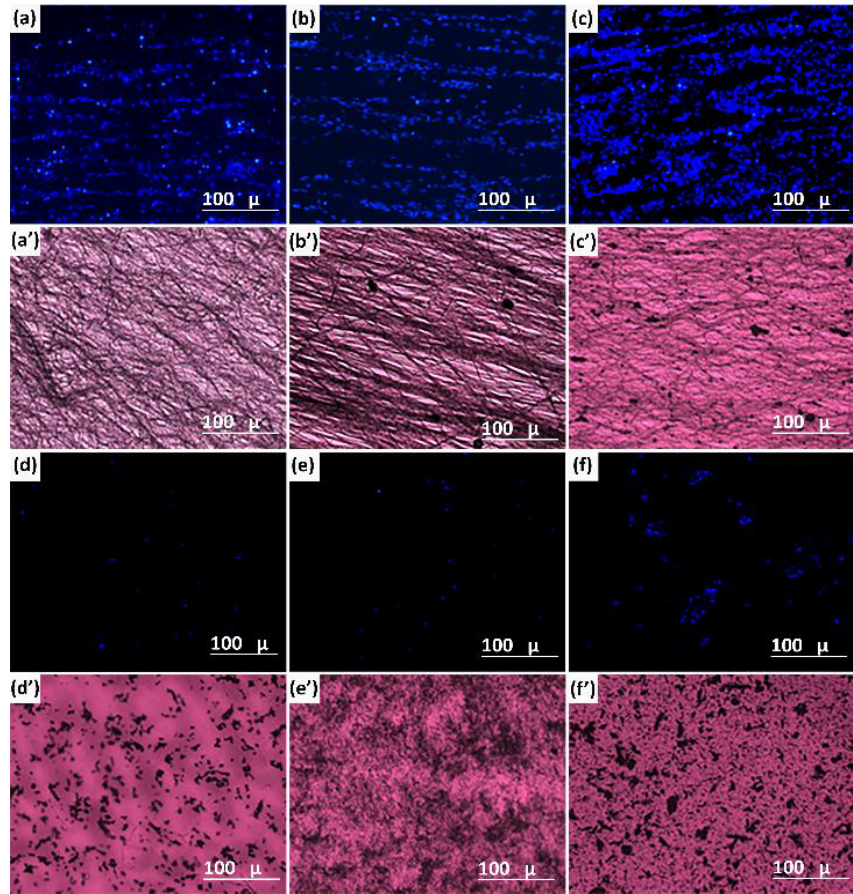

Figure 5: Fluorescent microscope images of fixed HLE cells stained with DAPI and grown on CB, CNF or graphene fiber-based scaffolds (a), (b), (c) and their bright field corresponding images (a'), (b') and (c'). Images of DAPI stained cells grown on thin film scaffolds for CB (d), CNF (e) and graphene (f) and their respective bright field images (d'), (e') and (f').

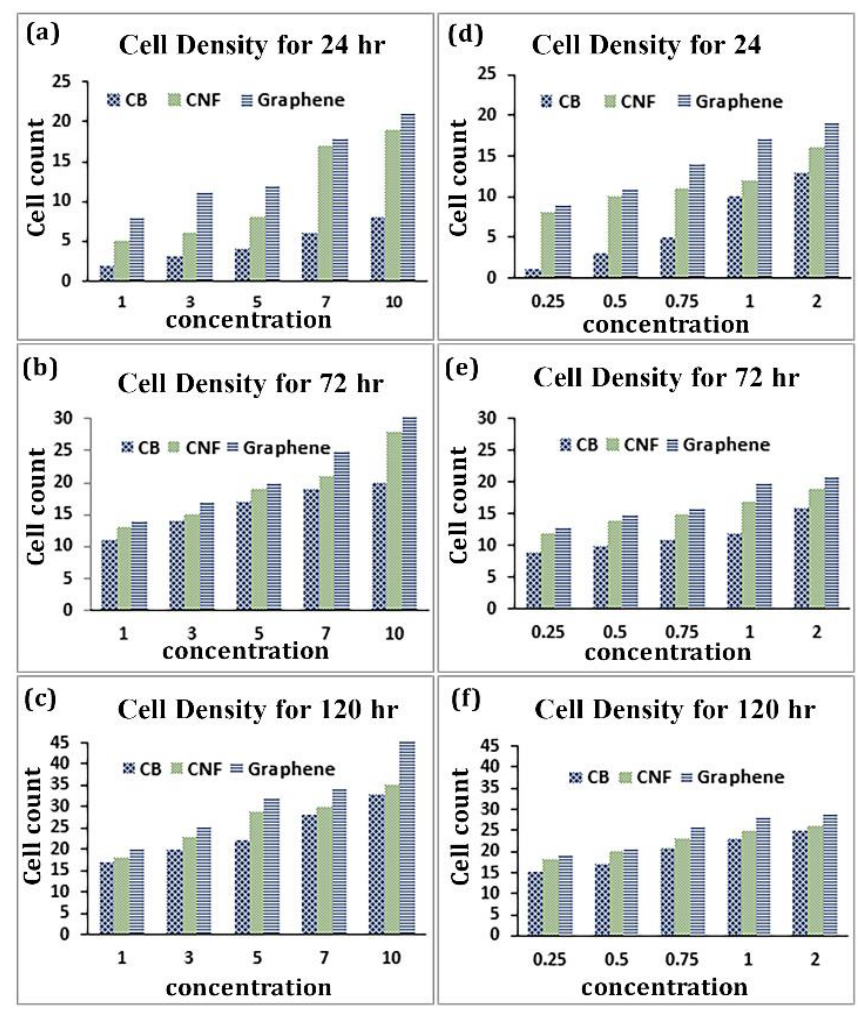

Figure 6: Cell density measured by counting DAPI+ cells grown on thin film scaffolds (a) $24 \mathrm{~h}$, (b) $72 \mathrm{~h}$ and (c) $120 \mathrm{~h}$ after plating. Cell density measured by counting DAPI+ cells grown on electrospun fiber scaffolds (d) $24 \mathrm{~h},(\mathrm{e}) 72 \mathrm{~h}$ and (f) $120 \mathrm{~h}$.

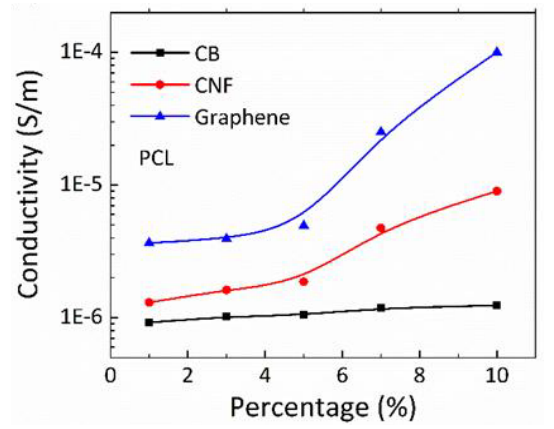

Figure 7: The relationship between the conductivity \& concentration of the nano-additive with $\mathrm{PCL}$ systems.

concentration and nano-additive type, the cell density was higher in samples made by electrospinning compared to the samples made by spin coating (Figure 5).

HLE cells were able to grow well on electrospun scaffolds and seem to grow parallel to the fiber orientation of electrospun scaffolds. The high surface area-volume ratio of fiber scaffold confirms a suitable area for cell attachment which allows the cells to be directed compared with a nonaligned scaffold [52]. On the other hand, cells grown on spincoated scaffolds (Figure 5d-5f) display a random pattern and the cell density was much less than that of cells grown on electrospun caffolds. Interestingly spin coated scaffold made with graphene were more favorable for cell growth than ones made with CNF and CB.

Analysis of the cell density during 24, 72 and 120 hours on fiber and spin coated scaffolds are depicted in Figure 6. Using both types of scaffolds, we were able to note an increase in cell density that correlated with higher additive concentration. Cell density also increased with increasing incubation times.

In addition, graphene was more favorable for cell growth than the other two materials. These observations are consistent with a previous study stating the electrical behavior of nano-filler based PCL nanocomposite films as illustrated in Figure 7 [49].

We also studied the relationship between cell density and various additives of fiber and film scaffolds during a 24, 72 and 120-hour time period. The concentration of additives was kept constant at $1 \%$ wt as displayed in Figure 8. The cell density increased with longer incubation times and there was also a gradual increase in cell density for the scaffolds that consisted of graphene, CNF and CB.

An increase in scaffold surface conductivity may lead to an efficient absorption and deposition of serum proteins, which can aid in cell attachment and cell growth [53]. Our results support graphene as a superior scaffold for cell growth. The electrical conductivity of the nano-fillers, specifically graphene plays an important role in cell growth due to its ability to transport high electrical currents [54]. The higher electrical conductivity of graphene depends on two modes of bonding interactions: Van der Waals and covalent bonds, as well as on the zerooverlap semimetal (with both holes and electrons as charge carriers). In addition, each atom in graphene is connected to three other carbon atoms on the two-dimensional plane, leaving one electron freely available on the third dimension for electronic conduction. On the other hand, CNF also has covalent and Van der Waals bonds $[55,56]$ that could be responsible for its relatively higher value on conductivity and could explain its role in supporting cell growth. CB, however, has the least favored cell growth properties and this could be due to the 
Citation: Al Habis N, Lafdi K, Tsonis PA, Rio-Tsonis KD (2018) Enhancing the Cell Growth Using Conductive Scaffolds. J Nanomed Nanotechnol 9: 493. doi: $10.4172 / 2157-7439.1000493$

Page 5 of 6

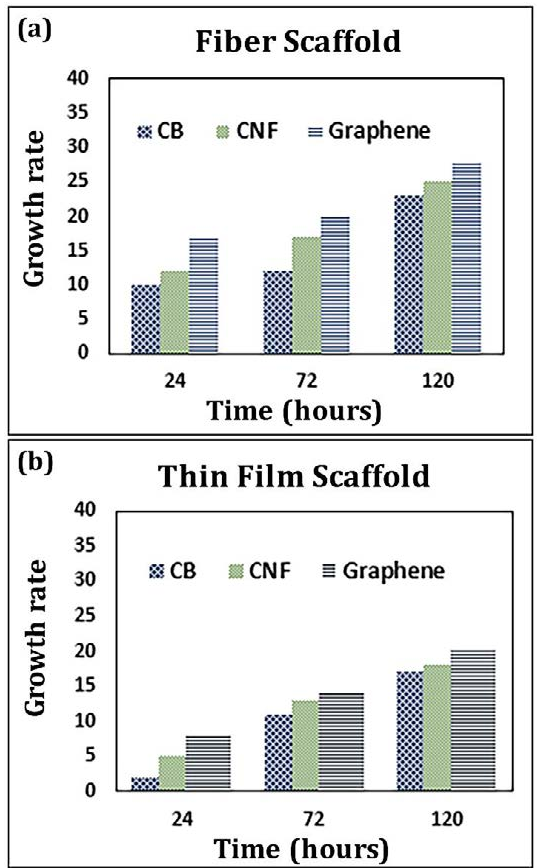

Figure 8: The relationship between cell density and time of incubation with 1 wt $\%$ of (a) fiber and (b) thin film scaffolds.

spherical onion like geometry and small grain size as well as the control of Van der Waals interactions between two adjacent particles reducing conductivity performance of the scaffold.

\section{Conclusion}

The biopolymer nanocomposites based on carbon nano-fillers have a positive effect on the behavior of cell growth. Regardless of the scaffold shape (film or fiber) and additive's type, when the concentration of nano-additives is increased, the electrical conductivity and the cell density increased too. For a given nano-additive's concentration and type, cell density increased in the scaffolds with fiber shape vs. the film. Importantly, as the conductivity of the scaffolds increased, so did the cell density.

As shown in this study, there is a close relationship between the electrical conductivity, cell density and scaffold orientation. An increase on conductivity can be achieved in two ways: by molecular orientation or/and by the appropriate selection of nano-additives such as graphene and nanotubes.

\section{References}

1. Czarnecki JS, Blackmore M, Jolivet S, Lafdi K, Tsonis PA (2014) Bone growth on Reticulated Vitreous Carbon foam scaffolds and implementation of Cellular Automata modeling as a predictive tool. Carbon 79: 135-148.

2. Dorati R, Colonna C, Genta I, Conti B (2011) Polymer scaffolds for bone tissue regeneration. Active implants and scaffolds for tissue regeneration. Springer, Berlin, Heidelberg 259-285.

3. Ravichandran R, Venugopal JR, Sundarrajan S, Mukherjee S, Ramakrishna S (2013) Cardiogenic differentiation of mesenchymal stem cells on elastomeric poly (glycerol sebacate)/collagen core/shell fibers. WJC 5: 28.

4. McCool JM, Rodriguez IA, Sell SA, Han Y, Bowlin GL (2014) A preliminary study on amelogenin-loaded electrospun scaffolds. J Bioact Compat Polym 29: 32-49.

5. Lai GJ, Shalumon KT, Chen JP (2015) Response of human mesenchymal stem cells to intrafibrillar nanohydroxyapatite content and extrafibrillar nanohydroxyapatite in biomimetic chitosan/silk fibroin/nanohydroxyapatite nanofibrous membrane scaffolds. Int J Nanomedicine 10: 567.
6. Ghasemi-Mobarakeh L, Prabhakaran MP, Morshed M, Nasr-Esfahani MH Ramakrishna S (2009) Electrical stimulation of nerve cells using conductive nanofibrous scaffolds for nerve tissue engineering. Tissue Eng Part A 15: 36053019.

7. Li M, Guo Y, Wei Y, MacDiarmid AG, Lelkes PI (2006) Electrospinning polyaniline-contained gelatin nanofibers for tissue engineering applications. Biomaterials 27: 2705-2015.

8. Jeong SI, Jun ID, Choi MJ, Nho YC, Lee YM, et al. (2008) Development of Electroactive and Elastic Nanofibers that contain Polyaniline and Poly (L lactide $\square$ co $\square \varepsilon \square$ caprolactone) for the Control of Cell Adhesion. Macromol Biosci 8: 627-637.

9. Li C, Hsu YT, Hu WW (2016) The regulation of osteogenesis using electroactive polypyrrole films. Polymers 8: 258.

10. Liu Y, Hu J, Zhuang X, Zhang P, Chen X, et al. (2011) Preparation and characterization of biodegradable and electroactive polymer blend materials based on mPEG/tetraaniline and PLLA. Macromol Biosci 11: 806-813.

11. Bendrea AD, Cianga L, Cianga I (2011) Progress in the field of conducting polymers for tissue engineering applications. J Biomater Appl 26: 3-84.

12. Silva GA (2006) Neuroscience nanotechnology: progress, opportunities and challenges. Nat Rev Neurosci 7: 65.

13. Nayak TR, Andersen H, Makam VS, Khaw C, Bae S, et al. (2011) Graphene for controlled and accelerated osteogenic differentiation of human mesenchymal stem cells. ACS Nano 5: 4670-4678.

14. Bajaj P, Khang D, Webster TJ (2006) Control of spatial cell attachment on carbon nanofiber patterns on polycarbonate urethane. Int J Nanomedicine 1 : 361-365.

15. Menaa F, Abdelghani A, Menaa B (2015) Graphene nanomaterials as biocompatible and conductive scaffolds for stem cells: impact for tissue engineering and regenerative medicine. J Tissue Eng Regen Med 9: 1321 1338.

16. Fan H, Wang L, Zhao K, Li N, Shi Z, et al. (2010) Fabrication, mechanical properties, and biocompatibility of graphene-reinforced chitosan composites. Biomacromolecules 11: 2345-2351.

17. Aoki N, Akasaka T, Watari F, Yokoyama A (2007) Carbon nanotubes as scaffolds for cell culture and effect on cellular functions. Dent Mater J 26: 178185

18. Donnet JB (1993) Carbon black: science and technology. CRC Press

19. Ivan C (1963) Carbon black preparation. United States patent US $3,073,681$

20. International Agency for Research on Cancer (2010) Carbon black, titanium dioxide, and talc. IARC Press, Lyon, France 39: 43-191.

21. Feng L, Xie N, Zhong J (2014) Carbon nanofibers and their composites: a review of synthesizing, properties and applications. Materials 7: 3919-3945.

22. Tibbetts GG (1989) Vapor-grown carbon fibers: Status and prospects. Carbon 27: $745-747$

23. Wangxi Z, Jie L, Gang W (2003) Evolution of structure and properties of PAN precursors during their conversion to carbon fibers. Carbon 41: 2805-2812.

24. Vilaplana JL, Baeza FJ, Galao O, Zornoza E, Garcés P (2013) Self-sensing properties of alkali activated blast furnace slag (BFS) composites reinforced with carbon fibers. Materials 6: 4776-4786.

25. Baeza FJ, Galao O, Zornoza E, Garcés P (2013) Multifunctional cement composites strain and damage sensors applied on reinforced concrete (RC) structural elements. Materials 6: 841-855.

26. Geim AK, Novoselov KS (2007) The rise of graphene. Nature materials 6: 183191.

27. Wang X, Shi $Y$ (2014) Fabrication techniques of graphene nanostructures. RSC Adv 1-30.

28. Krane N (2011) Preparation of graphene. Selected Topics in Physics: Physics of Nanoscale Carbon.

29. Yang F, Murugan R, Wang S, Ramakrishna S (2005) Electrospinning of nano/ micro scale poly (L-lactic acid) aligned fibers and their potential in neural tissue engineering. Biomaterials 26: 2603-2610.

30. Sharma AD, Zbarska S, Petersen EM, Marti ME, Mallapragada SK, et al. (2016) 
Citation: Al Habis N, Lafdi K, Tsonis PA, Rio-Tsonis KD (2018) Enhancing the Cell Growth Using Conductive Scaffolds. J Nanomed Nanotechnol 9: 493. doi: $10.4172 / 2157-7439.1000493$

Page 6 of 6

Oriented growth and transdifferentiation of mesenchymal stem cells towards a Schwann cell fate on micropatterned substrates. J Biosci Bioeng 121: 325-335.

31. Miller C, Shanks H, Witt A, Rutkowski G, Mallapragada S (2001) Oriented Schwann cell growth on micropatterned biodegradable polymer substrates. Biomaterials 22: 1263-1269.

32. Rutkowski GE, Miller CA, Jeftinija S, Mallapragada SK (2004) Synergistic effects of micropatterned biodegradable conduits and Schwann cells on sciatic nerve regeneration. J Neural Eng 1: 151-157.

33. Zou Y, Qin J, Huang Z, Yin G, Pu X, et al. (2016) Fabrication of Aligned Conducting PPy-PLLA Fiber Films and Their Electrically Controlled Guidance and Orientation for Neurites. ACS Appl Mater Interfaces 8: 12576-12582.

34. Kotwal A, Schmidt CE (2001) Electrical stimulation alters protein adsorption and nerve cell interactions with electrically conducting biomaterials. Biomaterials 22: $1055-1064$.

35. Ciombor DM, Aaron RK (1993) Influence of electromagnetic fields on endochondral bone formation. J Cell Biochem 52: 37-41.

36. Aaron RK, Ciombor DM (1993) Therapeutic effects of electromagnetic fields in the stimulation of connective tissue repair. J Cell Biochem 52: 42-46.

37. Goldman R, Pollack S (1996) Electric fields and proliferation in a chronic wound model. Bioelectromagnetics 17: 450-457.

38. Politis MJ, Zanakis MF (1989) The short-term effects of delayed application of electric fields in the damaged rodent spinal cord. Neurosurgery 25: 71-75.

39. Zanakis MF (1990) Differential effects of various electrical parameters on peripheral and central nerve regeneration. Acupunct Electro-Ther Res 15: 185-191.

40. Pomeranz B, Campbell JJ (1993) Weak electric current accelerates motoneuron regeneration in the sciatic nerve of ten-month-old rats. Brain Res 603: 271-278.

41. Sisken BF, Walker J, Orgel M (1993) Prospects on clinical applications of electrical stimulation for nerve regeneration. J Cell Biochem 51: 404-409.

42. Schmidt CE, Shastri VR, Vacanti JP, Langer R (1997) Stimulation of neurite outgrowth using an electrically conducting polymer. Proc Natl Acad Sci 94: 8948-8953.

43. Lovat V Pantarotto D, Lagostena L, Cacciari B, Grandolfo M, et al. (2005) Carbon nanotube substrates boost neuronal electrical signaling. Nano letters 5: 1107-1110.
44. Keisham B, Cole A, Nguyen P, Mehta A, Berry V (2016) Cancer Cell Hyperactivity and Membrane Dipolarity Monitoring via Raman Mapping of Interfaced Graphene: Toward Non-Invasive Cancer Diagnostics. ACS Appl Mater Interfaces 8: 32717-32722.

45. Guadagno L, Raimondo M, Vittoria V, Vertuccio L, Lafdi K, et al. (2013) The role of carbon nanofiber defects on the electrical and mechanical properties of CNF-based resins. Nanotechnology 24: 305704

46. Rey-Raap N, Calvo EG, Bermúdez JM, Cameán I, García AB, et al. (2014) An electrical conductivity translator for carbons. Measurement 56: 215-218.

47. Debelak B, Lafdi K (2007) Use of exfoliated graphite filler to enhance polymer physical properties. Carbon 45: 1727-1734.

48. Chen PH, Chung DD (2014) Thermal and electrical conduction in the compaction direction of exfoliated graphite and their relation to the structure. Carbon 77: 538-550.

49. Al Habis N, Liu C, Dumuids JB, Lafdi K (2016) Intelligent design of conducting network in polymers using numerical and experimental approaches. RSC Adv 6: 95010-95020.

50. Heidenreich RD, Hess WM, Ban LL (1968) A test object and criteria for high resolution electron microscopy. J Appl Crystallogr 1:1-9.

51. Noroozi M, Zakaria A, Radiman S, Wahab ZA (2016) Environmental synthesis of few layers graphene sheets using ultrasonic exfoliation with enhanced electrical and thermal properties. PloS One 11: e0152699.

52. Lim SH, Mao HQ (2009) Electrospun scaffolds for stem cell engineering. Adv Drug Deliv Rev 61: 1084-1096.

53. Yang H, Zhu G, Huang $Y$, Shi $X$, Wang $Y$ (2016) The stimulation of the differentiation of pheochromocytoma (PC12-L) cells into neuron-like cells by electrically conductive nanofibre mesh. Appl Mater Today 5: 215-222.

54. Gruber E, Wilhelm RA, Pétuya R, Smejkal V, Kozubek R, et al. (2016) Ultrafast electronic response of graphene to a strong and localized electric field. Nat Commun 7: 13948.

55. Kang I, Heung YY, Kim JH, Lee JW, Gollapudi R, et al. (2006) Introduction to carbon nanotube and nanofiber smart materials. Composites Part B: Eng 37: 382-394.

56. Vander Wal RL, Miyoshi K, Street KW, Tomasek AJ, Peng H, et al. (2005) Friction properties of surface-fluorinated carbon nanotubes. Wear 259: 738-743. 